\title{
Dois artistas de Minas Gerais na Semana de Arte Moderna: revisão e descentramento do modernismo de 22
}

\author{
Ivana Ferrante*
}

\begin{abstract}
Resumo
Este artigo traz à cena a participação de dois artistas de Minas Gerais na Semana de Arte Moderna: o poeta Agenor Barbosa e a pintora Zina Aita. Desconhecidos na contemporaneidade, Barbosa e Aita integram a lista dos que foram excluídos dos estudos sobre o festival de arte. Nos estudos correntes acerca da Semana de Arte Moderna, prevalece a ideia que propõe a episteme dos "deste lado da linha" como única a ser seguida, como bem fundamentou Boaventura de Sousa Santos (2007). A participação de Minas Gerais, rasurada pela história, pode ser vista como a voz do outro lado. Barbosa levou para os palcos do Theatro Municipal a integração do simbolismo com a "arte nova"; Zina Aita apresentou em suas telas as influências da vanguarda europeia e o colorismo excêntrico em diálogo com o barroco mineiro.
\end{abstract}

Palavras-chave: Semana de Arte Moderna. Agenor Barbosa. Zina Aita. Participação de Minas Gerais.

* Universidade Estadual de Montes Claros (UNIMONTES). Doutora em Letras. Professora titular da Universidade Estadual de Montes Claros. ORCID: http://orcid.org/000-002- 4650-1762. 


\title{
Two Artists from Minas Gerais in Modern Art Week: Review and Decentralization of Modernism of 22
}

\begin{abstract}
This article brings to the scene the participation of two artists from Minas Gerais in the Week of Modern Art: the poet Agenor Barbosa and the painter Zina Aita. Currently unknown, Barbosa and Aita are part of the list of those excluded from studies on the art festival. In current studies about the Week of Modern Art, the idea that proposes the episteme of "this side of the line" as the only one to be followed prevails, as Boaventura de Sousa Santos (2007) well founded. The participation of Minas Gerais, erased by history, can be seen as the voice of the other side. Barbosa took to the stages of the Municipal Theater the integration of symbolism with the "new art"; Zina Aita presented in her paintings the influences of the European avant-garde and eccentric colorism in dialogue with the Minas Gerais baroque.
\end{abstract}

Keywords: Modern Art Week. Agenor Barbosa. Zina Aita. Minas Gerais participation.

Recebido em: 27/09/2021 // Aceito em: 22/12/2021. 
O paradigma mais acionado para entender o primeiro momento do Modernismo brasileiro está ligado à ideia da hegemonia de um grupo que, decidido a romper com as influências passadistas na arte nacional, levou para os palcos do Theatro Municipal de São Paulo a irreverência e o espírito revolucionário contra as velhas formas artísticas. A Semana de Arte Moderna, como ficou conhecido o evento, realizou-se em três dias, 13, 15 e 17 de fevereiro de 1922, sob o patrocínio da oligarquia cafeeira e sob a inspiração de movimentos de vanguarda que, vindos da Europa, chegavam em várias regiões do Brasil.

A maioria dos estudos que se desenvolvem acerca da Semana de Arte Moderna, costumam se repetir. Mário da Silva Brito, em 1958, publica História do modernismo brasileiro: Antecedentes da Semana de Arte Moderna, uma revisão abrangente dos fatos, nomes e publicações que integraram a organização e realização do evento. Esse importante estudo de Brito tem servido de base a muitos que se dedicaram às pesquisas sobre o tema, ficando tais estudos, todavia, na maior parte, centralizados nos mesmo sujeitos e fatos. Uma rápida verificada nos bancos das teses disponibilizadas nas universidades do país revela que a primazia dos estudos se concentra nas universidades paulistas - o que não se constitui surpresa, visto que o palco do festival artístico acontece na capital São Paulo - e em torno dos nomes de Mário de Andrade, Oswald de Andrade, Tarsila do Amaral e Anita Malfatti. Nomes como Graça Aranha, Di Cavalcanti, Guilherme de Almeida, Victor Brecheret e VillaLobos aparecem com menos frequência; Menotti Del Picchia, um dos mais ardorosos defensores da "arte nova" e responsável pela conferência que abriu a mostra de arte do dia 15 de fevereiro de 1922, raramente é lembrado, assim como o da pianista 
Guiomar de Novais. De qualquer forma, ainda que nem todos os integrantes fossem de São Paulo, a Semana foi tomando feições paulistanas e, naturalmente, foram obnubiladas contribuições importantes, inclusive regionais, à ideia de arte moderna que, então, defendiam.

Em 1942, na célebre conferência lida no Salão da Biblioteca do Ministério das Relações exteriores do Brasil, em que faz uma revisão da já famosa Semana de Arte Moderna, Mário de Andrade afirma que "[o] Modernismo, no Brasil, foi uma ruptura, foi um abandono de princípios e de técnicas consequentes, foi uma revolta contra o que era a Inteligência Nacional [...]" (ANDRADE,1974, p. 235). Ressalte-se que foi ele o responsável pelo termo Modernismo, consagrado por nossa historiografia literária, depois de acontecida a buliçosa Semana. A leitura de jornais e revistas da época que se posicionavam sobre o movimento usam os termos "arte nova", "credo novo" ou "futurismo". Tal confusão permanece em toda a década de 1920.

Nessa conferência, o criador de Macunaíma (1928), numa postura revisionista reconhece que aqueles rapazes e moças que se reuniam para falar sobre a nova arte brasileira constituíam grupos distintos, que, por vezes, discordavam em vários aspectos, unidos em torno do desejo comum de mostrar ao público brasileiro uma arte com dicção própria, desvinculada das influências academicistas. Outros participantes do festival também fizeram suas revisões, chamando a atenção para o que fora esquecido ou desprezado pela crítica, em detrimento de uma ideia mais abrangente acerca do evento.

$\mathrm{Na}$ contemporaneidade, especialmente com a iminência das comemorações do centenário da Semana, estudiosos de 
diferentes áreas do saber propõem discussões, controvertidas às vezes, sobre as origens do modernismo brasileiro. São vozes que não só revelam dicotomias entre modos de interpretação e de definição do que entendem por modernismo, mas que também apresentam clivagens regionais, envolvendo lugares, intelectuais e exposições, ocorridas fora do eixo paulista. A visão predominante, contudo, considera que o início do movimento se deu em São Paulo, em 1922, cujo epicentro foi a Semana de Arte Moderna, justamente por ter sido esse festival o aglutinador de várias expressões artísticas - música, dança, artes plásticas e literatura. Também se considera, sob esse aspecto, o palco do Theatro Municipal de São Paulo, originalmente conservador e elitista, e o próprio mecenato da Semana, advindo da elite paulista que, sob uma ótica de aceitação ou repulsa, contribuíram, de certa forma, para a divulgação do evento. Conforme entrevista de Marinette Prado, esposa de Paulo Prado, um dos patrocinadores da Semana, concedida a Aracy Amaral, a sugestão de organizar uma Semana de Arte, inspirada nos festivais de arte de Deauville, foi dela (AMARAL, 1998). ${ }^{1}$

A construção do nosso modernismo deu-se com a importação inicial das inovações estéticas advindas da Europa, embora possamos considerar que, desde o início, o cosmopolitismo mesclava-se a um espírito nacionalista presente em manifestações importantes, convocadas, por esse motivo, para integrarem a Semana, como a do escritor Menotti Del Picchia, já conhecido por ser o autor de Juca Mulato (1917), livro que aborda a questão da mestiçagem e é ambientado no interior de São Paulo.

1 Semaine de Fêtes Deauville, França. Deauville foi centro catalizador de muitos eventos artísticos e culturais, aglutinando ideias e linguagens inovadoras. Distingue-se por sua feição elitista. 
A recepção do Futurismo, por exemplo, corrente estética importada da Itália, não veio sem polêmicas, em parte geradas pelo espírito nacionalista que se fortalecia, à medida que se aproximava a data do centenário da independência do Brasil. Colocadas à parte, essas questões não foram suficientes para calar alguns dos valores futuristas que integraram as discussões estéticas do nosso modernismo. ${ }^{2}$ Em considerável parte dos poemas apresentados na Semana, percebe-se nítido esforço dos escritores em adaptarem seus versos às requisições vanguardistas, preconizadas no manifesto de Marinetti.

As polêmicas em torno do movimento modernista começam antes de 1922, conforme sabemos. Além da contestada exposição de Anita Malfatti, em 1917, que gera a ruidosa reação de Monteiro Lobato, consideramos ainda que, no âmbito da literatura, havia dissenções. Em 1921, Oswald de Andrade publica artigo intitulado $\mathrm{O}$ meu poeta futurista, nas páginas do Jornal do Comércio, no qual também estão versos inéditos de Pauliceia Desvairada. $\mathrm{O}$ artigo provocou transtornos a Mário de Andrade, que chegou a perder alunos no Conservatório Musical de São Paulo. Em réplica, também publicada pelo Jornal do Comércio, datada de 6 de junho de 1921, o escritor rechaçou veementemente a condição de futurista, por meio de argumentos em que afirmava seu catolicismo praticante, tentando amenizar as influências vanguardistas que os poemas traziam.

Houve, ao longo da história, várias posições críticas sobre o movimento, vindas também de alguns que integraram as linhas de frente do modernismo. Rubens Borba de Moraes lembra, em artigo publicado no Correio Brasiliense, em 1970, que grande parte da população brasileira em 1922 não era formada pela

2 E preciso salientar que havia uma confusão generalizada quanto à nomenclatura das novas tendências. A imprensa das duas primeiras décadas de século XX invariavelmente se refere ao futurismo como sinônimo da arte nova ou moderna. 
burguesia, mas composta por coronéis e bacharéis patrioteiros que se ufanavam do país como "crianças que admiram o papai". Ivan Marques, em Cenas de um modernismo de província (2011), adverte que o conceito de modernismo no Brasil é tão vasto e impreciso, no decorrer do tempo, que, às vezes, sentimos a necessidade de usar o termo no plural - modernismos.

O final da década de 1970 vive momentos de revisionismo crítico, marcados pela emergência de contestações que iam desde o carácter efetivamente moderno do movimento brasileiro até as discussões acerca das dissonâncias produzidas por ele, visíveis até mesmo na centralidade dos acontecimentos, em pleno Theatro Municipal, em 1922. Na contemporaneidade, as revisões sobre o Modernismo incidem principalmente sobre a noção de hegemonia brasileira, paradigma ao qual se contrapõe a leitura pós-colonial, que critica as permanências de práticas e dinâmicas hegemônicas responsáveis pelas desigualdades abissais dentro de sociedades colonizadas. Sob o tópico, servenos o entendimento de Boaventura de Sousa Santos sobre a "ecologia dos saberes" e as questões que este sublinha cerca do pensamento abissal. Nos estudos correntes acerca da Semana de Arte Moderna, prevalece a ideia que propõe a episteme dos "deste lado da linha" como única a ser seguida, como bem fundamentou Boaventura de Sousa Santos (2007).

Santos trata dessa questão no texto Para além do pensamento abissal (SANTOS, 2007), em que observa a coexistência de presenças, de "interidentidades", mesmo que estas se manifestem a partir de um pensamento ou identidade hegemônica, desconsiderando a pluralidade de sentidos e de interpretação do mundo. O pensamento abissal, na opinião de Santos, constrói subalternidades, não considera a exclusão social 
e a compreensão ampla do mundo. Boaventura de Sousa Santos discorre sobre essas discrepâncias de agentes de produção e validação de sentido, quando afirma que existe um pensamento abissal fomentado pelo ocidente. Há, de acordo com o sociólogo, uma distinção entre "deste lado da linha" e "do outro lado da linha", entendendo essa linha como algo imaginário que legitima certas práticas sociais e econômicas e desconsidera outras: "Tudo aquilo que é produzido como inexistente é excluído de forma radical porque permanece exterior ao universo que a própria concepção de inclusão considera como o 'outro' [...]” (SANTOS, 2007, p. 71). Essa divisão provoca o desaparecimento de "o outro lado da linha", torna-o inexistente. Por isso, Boaventura de Sousa Santos advoga pela "ecologia dos saberes". Na esfera da literatura, essa "ecologia" permitiria a representação do abismo social, não só na produção do tecido (texto) literário, mas também na legitimação de todo o imaginário do que é visto como literatura. Assim sendo, sob os pressupostos da "ecologia dos saberes", seria necessário reconhecer o registro literário das minorias sociais, étnico-raciais e de gênero.

Não podemos deixar de mencionar a importância atribuída por Mário de Andrade a Anita Malfatti, que, em 1917, tornara-se alvo de polêmica devido ao artigo dessacralizador de Monteiro Lobato. No livro em que aborda os antecedentes da Semana de Arte Moderna, Mário da Silva Brito observa que o poeta modernista associaria à pintora o papel de estopim do modernismo; em torno do seu nome reuniu-se a força aglutinadora dos jovens rebeldes que se juntaram e realizaram a Semana de Arte Moderna de 1922.

Apropriadamente, sob a baliza dos estudos de Boaventura de Sousa Santos, olhares críticos sobre o movimento inspiram perguntas acerca da não representatividade dos grupos 
minoritários na Semana de 22. Embora consideremos que Mário de Andrade era negro e que houve, no recital, a participação reconhecida das pintoras Anita Malfatti e Tarsila do Amaral, incomodam-nos as ausências nos palcos do Municipal em 1922 tanto quanto as presenças que lá estavam, mas que o tempo, e certamente os estudos que consagraram o Modernismo brasileiro rasuraram ou desprezaram.

\section{2 "Uma tristeza mineira numa capa de garoa"3}

A notícia de uma projetada Semana de Arte Moderna, em São Paulo, foi recebida com um prêmio de curiosidade, misto de entusiasmo, nas nossas rodas intelectuais e altamente mundanas. E era natural que assim acontecesse! É a primeira vez que se vai tentar, no Brasil, um certame dessa natureza. (PICCHIA, 1922, p. 4)

Os jornais da época, mesmo os da capital paulista, noticiam de forma tímida o vernissage que se preparava, muito mais barulhento no ímpeto exaltado dos jovens idealizadores que nas notícias e efeitos que temos sobre ela, no calor da hora. Exceto pelo caso isolado do Correio Paulistano (1854-1963), que tinha Menotti Del Picchia como entusiasta redator, vemos notícias esparsas (e, na sua maioria, detratoras) sobre A Semana de 22. Os demais órgãos da imprensa utilizavam expressões como "subversores da arte", "espíritos cretinos e débeis" ou "futuristas endiabrados" para caracterizar o grupo de artistas inovadores.

O Correio Paulistano era ligado ao Partido Republicano Paulistano (PRP), dirigido e sustentado por aristocratas e tradicionalistas, no entanto, abria espaço para manifestações

3 O título é inspirado numa definição que Menotti Del Picchia confere ao poeta mineiro Agenor Barbosa, publicada em sua coluna Crônica Social, no Correio Paulistano, 1921. 
exaltadas sobre a "arte futurista", sobretudo na coluna Chronica Social, assinada por Hélios, pseudônimo de Menotti Del Picchia. De acordo com Lilia Schwarcz (1987 apud Thalassa, 2007), "o Partido Republicano é uma adaptação das ideias originais liberais às práticas da elite brasileira"; o PRP configuravase como uma de suas bases e era ligado aos cafeicultores, aos grandes proprietários. Como podemos perceber, estão no cerne da república brasileira as contradições explicitadas nas páginas do Correio Paulistano e na própria organização da Semana de 22, que aglutinava em torno de si artistas que negavam o passadismo e mantinham inegáveis laços com a tradição.

De acordo com Marcos Augusto Gonçalves, em 1922: a semana que não terminou (2012), muitos desses artistas pertenciam a famílias ricas ou influentes, "educaram-se à europeia, aprenderam línguas e frequentaram boas escolas [...]" e estavam vinculados "aos extratos mais afortunados e cultos da grande cidade emergente do Brasil [...]" (GONÇALVES, 2012, p. 31). O poeta Guilherme de Almeida assim definiria o grupo, no Suplemento Literário d'O Estado de São Paulo, em 1962: "Éramos os playboys intelectuais de 1922 [...]". Tida por alguns como um momento propulsor, uma divisão de águas, a Semana de Arte Moderna condensou espíritos jovens e inflamados, tendências e linguagens artísticas diferentes e adeptos de distintos lugares.

No livro Cenas de um modernismo de província (2011), Ivan Marques reflete sobre o movimento modernista de Minas Gerais, formado pelo grupo de escritores mineiros - Drummond, Emílio Moura, João Alphonsus e Cyro dos Anjos - atuantes na escrita e na primeira manifestação notadamente modernista, na cidade de Belo Horizonte, entre os anos 1920 e 1930, destacando 
as diferenças do grupo mineiro em relação aos grupos surgidos no Rio de Janeiro, no Rio Grande do Sul e no Nordeste brasileiro, o que realça a noção de que o Brasil contou com vários "modernismos", como hoje se sabe. Na descrição do grupo de Belo Horizonte, o escritor ressalta que, para além das influências do grupo paulista, especialmente sentida depois da viagem de 1924 a terras mineiras, em Minas Gerais o movimento adquiriu feições particulares, determinada pelas condições locais, nas quais se incluem o traço provinciano (apego às tradições, por exemplo), expresso no título de seu livro.

Ainda, conforme se sabe, os modernistas de Belo Horizonte, eram provenientes de cidadezinhas do interior, filhos de famílias tradicionais, algumas atreladas a grupos políticos conservadores, assim como seus antecessores da imprensa. O espaço dos cafés era utilizado para dar vazão ao espírito debochado, crítico e jovial que, mais tarde, eclodiria nos versos de Drummond e, em tons diferentes, na prosa de Pedro Nava e de Cyro dos Anjos.

As revistas Vita, A Vida de Minas e o jornal Diário de Minas revelam que, antes de 1922, ano de realização da Semana de Arte Moderna, e antes do conhecido Grupo Estrela, uma modernidade mineira estava sendo gestada em Belo Horizonte, acalentada com a chegada de jovens do interior do estado que vinham à nova capital para atuar como funcionários públicos e escrever versos. Esses poetas de gabinete deram o tom literário do momento inicial do século XX em Belo Horizonte, misturando o tom passadista ao entusiasmo pela novidade. Desse grupo, citamos alguns nomes que aparecem com maior frequência em Vita e A Vida de Minas: Agenor Barbosa, Abílio Barreto, Alphonsus de Guimaraens e seu irmão, Archangelus de 
Guimaraens, Augusto de Lima, Alzira Reis, Julinda Alvim. ${ }^{4}$ Eles foram os antecessores de Carlos Drummond de Andrade, Cyro dos Anjos, Pedro Nava, Emílio Moura, Abgar Renault.

Antes do contato com Mário de Andrade e Oswald de Andrade, as notícias das vanguardas europeias e das renovações artísticas demandadas pelas requisições do século XX deixavam, em terras mineiras, algumas sementes. A atmosfera conservadora e academicista que reinava na recém-inaugurada Belo Horizonte misturava-se às demandas de progresso urbano e às mudanças estéticas da época, como definiam os editoriais de Vita e A Vida de Minas, revistas que anunciavam os progressos da construção da nova capital e davam notas sobre publicações de livros, mostras culturais, além de publicarem poemas, contos e crônicas, em suas páginas. Aos cálculos dos construtores somavam-se, desde o início da projeção da nova capital, a tinta e o papel de jornais e revistas.

Nessa atmosfera, encontramos rastros de Agenor Barbosa, que trabalha como cronista e redator das revistas Vita (19131914) e Vida de Minas (1915-1916) e como repórter do Diário de Minas. Contando com apenas 17 anos, o jovem poeta, nascido em Montes Claros, Minas Gerais (1896-1977), mudase com a família para Belo Horizonte, onde se firma como jornalista e poeta. Seus poemas, nesse período, têm claras influências simbolistas. No livro Uma tristeza mineira numa capa de garoa - Agenor Barbosa; um poeta mineiro na Semana de Arte Moderna (REBELLO E PAULA, 2020), recolhe-se parte da produção poética de Barbosa nas revistas mineiras: No São Francisco (1914); Pelo Inverno (evocação) (1914); Novela de

\footnotetext{
4 Registramos a participação das mulheres escritoras, a publicação de um artigo de três páginas sobre o feminismo (1913, revista Vita), uma frequência de matérias sobre publicação de livros, no cenário brasileiro e internacional, notícias de concursos de poemas e de traduções.
} 
maio (1914); Da legenda do amor e da vida- I (1915); Ícaro (1915); Soneto (1914); Sonho dantesco (1916); Saudade (1916); Aspiração da pedra (1916); Pela França (1916); Da legenda do amor e da vida- II (1916); Últimas pedrarias (1916), e Sonata ao luar - Beethoven OP. 16 (1917).

Em 1917, Agenor Barbosa muda-se para São Paulo, onde conhece os jovens idealizadores da Semana de Arte Moderna: Mário de Andrade, Oswald de Andrade, Menotti Del Picchia, Graça Aranha, e outros. Em notícia de 1921, intitulada Futurismo Paulista, ${ }^{5}$ Sérgio Buarque de Holanda compara os modernistas paulistas à vanguarda francesa. Entre esses "futuristas" de São Paulo, após relacionar Oswald de Andrade, Menotti Del Picchia, Mário de Andrade e Guilherme de Almeida, Holanda acrescenta à lista: "Seria injusto esquecer os outros nomes de valor como Moacir Deabreu, Ribeiro Couto, Agenor Barbosa e Afonso Schmidt, que, embora não sejam todos paulistas, nem por isso deixam de colaborar ativamente para seu progresso literário.”.

Em História do Modernismo Brasileiro. Antecedentes da Semana de Arte Moderna, Mário da Silva Brito ([1958]/1974), ${ }^{6}$ ao mencionar a "doutrinação reformista" que inspirava o grupo de entusiastas da arte nova, declara que Agenor Barbosa integrava o grupo que articulou e planejou o recital do Theatro Municipal de São Paulo, de 1922:

Toda a doutrinação reformista, efetivada em 1921 como preparo à Semana de Arte Moderna, apoia-se neste esquema, que é acrescido, depois, de alguns novos princípios e de inúmeros argumentos. Doutrinação que se encontra explanada numa série de artigos de Oswald de Andrade, de Menotti Del Picchia, de Cândido Mota Filho, de Agenor Barbosa, de Mário de Andrade, que

5 Publicado na revista Fon-Fon, em 10 de dezembro, de 1921.

6 A data entre colchetes indica o ano de publicação original da obra, que somente será indicada em primeira citação neste texto. Nas seguintes, será registrada apenas a data da edição consultada pelos autores. 
são os mais ativos polemistas do grupo [...] (BRITO, 1974, p. 191).

Nem todos os nomes, conforme sabemos, atuaram com o mesmo peso na organização do evento e na cena principal de todas as decisões. Nesse sentido, é preciso ressaltar as questões geradas pela relação entre a poesia que se modernizava e a presença diferenciadora da realidade histórica e social brasileira. O grupo era formado por uma turma bastante eclética, que se distinguia entre os que tinham os ânimos mais exaltados, como Menotti Del Picchia, Oswald de Andrade e Mário de Andrade e aqueles representados por um Ronald de Carvalho ou por um Guilherme de Almeida, por exemplo, assim como Ribeiro Couto, cujas produções poéticas do período poderiam ser caracterizadas como expressão da transição entre as tendências parnasianas, ainda presentes, e as influências do Simbolismo. Podemos notar, na maioria dos poemas conhecidos, apresentados ao público durante a realização da Semana de Arte Moderna, que foram feitas, por parte de alguns escritores do conhecido grupo de artistas, tentativas de adaptação à "nova arte" que nem sempre resultaram em expressões legítimas da arte renovadora e futurista que todos pleiteavam. 


\section{Dois mineiros na Semana de Arte Moderna}

\section{Imagem 1 - Páginas do programa da Semana de Arte Moderna de 22}

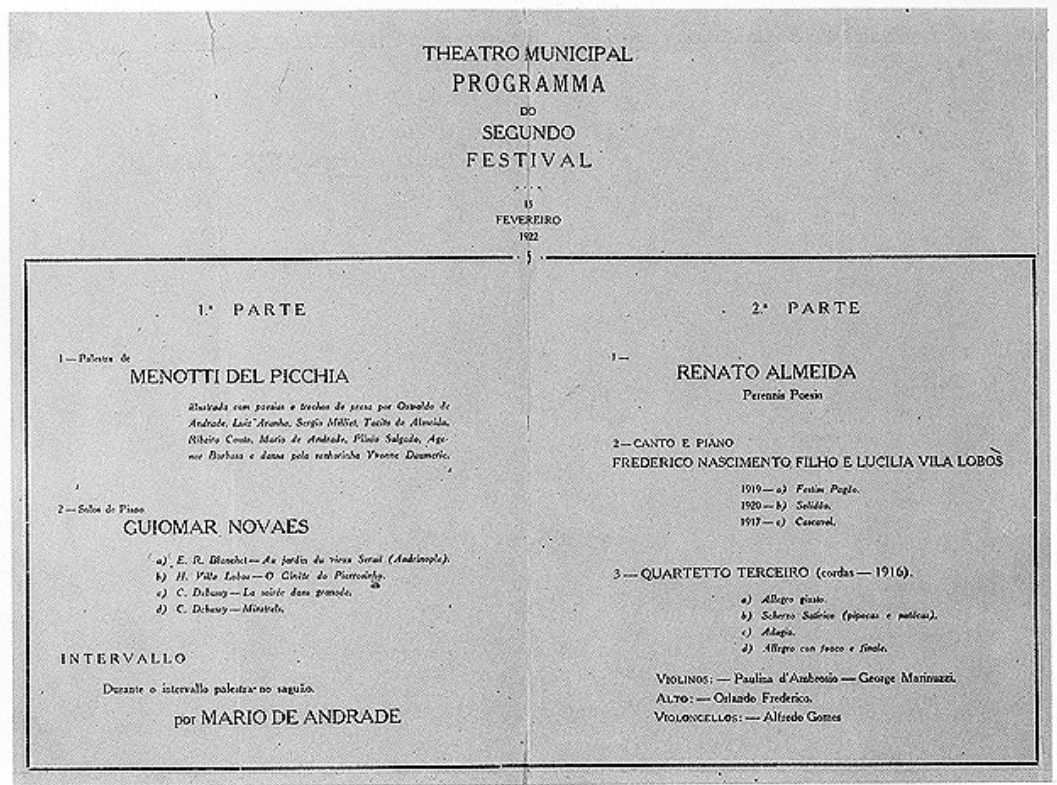

Fonte: Acervo do Instituto de Estudos Brasileiros (USP - Arquivo Mário de Andrade).

O Programa oficial da Semana de Arte Moderna informa que, no primeiro dia de apresentações, 13 de fevereiro, Graça Aranha ministrará sua conferência, intitulada: A emoção estética na arte moderna. Para o segundo dia, 15 de fevereiro, anunciase o discurso de Menotti Del Picchia, seguido por um recital de poemas em que participam Luís Aranha, Sérgio Milliet, Tácito de Almeida, Ribeiro Couto, Mário de Andrade, Plínio Salgado e Agenor Barbosa. 
Esse segundo dia foi precedido por uma matéria, sob o título Segunda batalha, que dava publicidade à primeira noite do evento e preparava os ânimos do público leitor para as apresentações do dia 15, publicada no Correio Paulistano e assinada pelo colunista Hélios, pseudônimo de Picchia, reproduzida aqui parcialmente:

Feriu-se, segunda-feira, no Teatro Municipal, entre a cultíssima e aristocrática plateia de São Paulo, e o grupo escarlate dos "futuristas", a primeira batalha da Arte Nova. Não houve mortos e feridos. Acabou num triunfo. Graça Aranha, Guilherme de Almeida, Ribeiro Couto, Villa-Lobos, os heróis já lendários da primeira refrega, saíram da justa apoteoticamente, coroados de aplausos. Hoje, entra em combate um novo contingente de forças: é brilhante e tem antecipadamente garantida sua vitória, pois leva como segura "mascote" o apoio dessa glória universal que é Guiomar Novaes. O programa promete coisas do arco-íris: começará por uma palestra de Hélios, que apresentará o grande romancista Oswald de Andrade; depois, esse terrível criador da "Paulicéia Desvairada", que é o erudito e pacífico Mário de Andrade; depois Álvaro Siqueira, Agenor Barbosa, Luís Aranha, Plínio Salgado. [...] São Paulo super esteta encherá as poltronas e frisas do Municipal, hoje à noite, pois, como a da primeira batalha, estamos certos de que ornarão a plateia todas aquelas aristocráticas flores da aristocracia patrícia, que transformaram segunda-feira o nosso teatro máximo numa admirável "corbeille" de elegância, de beleza e de espírito. (PICCHIA, 1922, p. 4).

O texto representa o entusiasmo de Menotti Del Picchia, envolvido diretamente nos preparativos do evento e ardente defensor da "arte futurista" - nome genérico que, então, era usado pelos jovens modernistas para definir o espírito de turbulência e a defesa da arte nova, como costumavam dizer. $\mathrm{O}$ primeiro dia do evento, que contara com a tranquilizadora presença de Graça 
Aranha, o mais velho e experiente dos participantes da Semana, não anteciparia os acontecimentos do dia 15 de fevereiro, dedicado especialmente à poesia. A retórica inflamada do palestrante, seguida da récita dos poetas anunciados, foi recebida com vaias. Menotti Del Picchia cita alguns versos: "Pela estrada de rodagem da via láctea, os automóveis dos planetas correm vertiginosamente", que evocavam o poema Canto real da estrada de rodagem, de Agenor Barbosa.

Massaud Moisés, em História da Literatura Brasileira, v. 3, Modernismo, afirma que Agenor Barbosa foi o único aplaudido, na barulhenta noite dedicada à poesia, referindo-se ao segundo dia do festival de arte. Marcos Augusto Gonçalves observa (2012, p. 307): "Sobre Agenor Barbosa, de quem pouco se falou depois da Semana, teria sido o único aplaudido, na noite de vaias, supostamente por não ser um futurista. No entanto, ele leu no Municipal um poema de dicção futurista - 'Os pássaros de aço' - que, segundo Silva Brito, Oswald elogiava [...]”.

Gonçalves ainda menciona Barbosa, citado por Plínio Salgado, na Ilustração Brasileira, em maio de 1922, como o "poeta raro da cidade moderna", destacando nele "as emoções atuais" e nostálgicas que, às vezes, predominava entre os paulistanos. Para Salgado, citado por Gonçalves (2012, p. 307), era a "melancolia racial" a debater-se na "onda formidável do progresso [...]".

Mário da Silva Brito (1974) é quem dedica maior espaço ao poeta Agenor Barbosa, sem, contudo, mencionar sua origem mineira. $\mathrm{O}$ nome do poeta é citado várias vezes no estudo de Brito, especialmente no Capítulo 13, intitulado A divulgação da nova estética, que lê a crônica Um Poeta, de Menotti Del Picchia, publicada no Correio Paulistano, em 30 de abril de 1921, em 
que Picchia apresenta Agenor Barbosa. Brito transcreve do artigo do autor de Juca Mulato três poemas de Barbosa com os quais exemplifica a nova poética brasileira: O que eu vi nessa noite; Canto Real da estrada de rodagem, e Vida Boêmia, seguidos de breve análise (BRITO, 1974, p. 217-219).

Nos poemas que Barbosa compõe em 1920, 1921 e 1922 percebe-se uma aproximação entre o desejo de transcendência e a referência à cidade de São Paulo e à tecnologia moderna. No poema Os pássaros de aço, apresentado na Semana de Arte Moderna, o poeta conjuga estrofes inequivocamente simbolistas, tais como: "De subir no seu Sonho e na sua Ânsia! / De ver tudo que acena na distância / E que, jamais, pôde atingir [...]" com passagens de métrica livre como: "Em semicírculos, como uma ave de rapina, / Subiu num rufo de motor / Dominador [...]" (REBELLO, PAULA, 2020, p. 171). Embora sejam tentativas de se adequar ao gosto futurista, elas revelam, justamente pelo modo explícito como aparecem, um problema real para a poesia de então que era o de afirmar a estética da rapidez e da simultaneidade sem perder a disciplina aprendida no Parnasianismo e as inclinações subjetivas do Simbolismo. A demanda de atualização poética, que atendia pelo nome de "futurismo", não é suficientemente forte para eliminar as influências passadistas. Surgia, portanto, no confronto entre as tendências, uma poesia híbrida que, do ponto de vista histórico, mostra-se interessante.

A seguir, versos do poema Canto real da estrada de rodagem, publicado originalmente no Correio Paulistano, em abril de 1920, em que se percebe o apelo à vida urbana, com imagens do progresso e da vida urbana, tão caros ao futurismo:

O automóvel rodou pela estrada poeirenta, Longe, o ocaso era todo uma nódoa sangrenta... $[\ldots]$ 
Como o desejo humano e a ambição que não se finda, desdobrava-se, ao longe, a curva do horizonte.

Atrás de um alto monte erguia-se outro monte...

E, na distância, a estrada estendia-se ainda...

Onde o pouso, onde a fonte hibernal e sonora, em que, parando o apocalítico motor, ao canto da água e ao bucólico frescor, descer e descansar, sob a paz daquela hora?

$[\ldots]$

Passa a vila. Crepúsculo. Anoitece...

Uma lua cinematográfica aparece...

E só se escuta pela noite erma e calada, dentre a sombra noturna, o rumor trepidante do motor ofegante do automóvel, galgando uma curva na estrada...

Acendem-se os faróis...

Pirilampejam luzes, longe como sóis...

E a lua, imaterial, rola sobre a paisagem como o automóvel pela estrada de rodagem.

Os versos deixam transparecer a tensão do apelo ao novo com as requisições do passado, numa visão quase contraditória entre o que a imagem exalta (o automóvel, a estrada de rodagem, a cidade) e o que o eu lírico experimenta e busca (o pouso, a paz, a fonte hibernal e sonora, o canto da água e o bucólico frescor). Esse desconforto é também visível na aporia entre o tema do poema (o carro, na estrada), cujo campo semântico remeteria o leitor à ideia de velocidade e o ritmo do poema, lento, intensificado pelo uso das reticências. Essa característica é reiterada na poesia de Barbosa, identificando visível desconforto do sujeito que vive na cidade grande, mas a ela não se integra.

No programa da Semana de Arte Moderna, também se lê o nome da pintora e ceramista mineira Zina Aita. Filha de empresários italianos imigrados, Tereza Aita, ou Zina, nome 
com que assinava seus trabalhos artísticos, nasceu em Belo Horizonte, em 1900. Entre 1914 e 1918, transfere-se com a família para a Itália e frequenta a Accademia di Belle Arti di Firenze, onde estuda com Galileo Chini, pintor e ceramista, ligado às artes decorativas. Em sua temporada na Itália, dedicouse ao desenho e à pintura, mantendo contato com as novidades que movimentavam as cidades de Roma, Florença, Milão e Veneza. A obra de Aita, conforme a crítica especializada, apresenta relações próximas à obra de Chini, de quem foi aluna, conhecido como grande colorista.

No dia 31 de janeiro, de 1920, a jovem pintora Zina Aita, de 20 anos, levou suas cores fortes a uma exposição de arte, realizada no Conselho Deliberativo, situado na esquina de rua da Bahia com a avenida Augusto de Lima, em Belo Horizonte. A exposição de 1920 foi um acontecimento individual, de iniciativa do diretor da primeira Escola de Belas Artes de Belo Horizonte, Aníbal Mattos, curador da mostra na capital mineira. Zina Aita já havia exposto no Rio de Janeiro, em 1919, razão por que chama a atenção de Mattos, que se formara na Escola Nacional de Belas Artes do Rio de Janeiro:

Belo Horizonte, cidade nova e formosa, começa a ter razão do orgulho de seus filhos. Já há uma geração moça que poderá, pelo brilho de sua inteligência, firmar a sua glória ao lado de outras cidades mineiras. As nossas escolas superiores já têm dado bacharéis, médicos e engenheiros, nascidos na cidade moça dos crepúsculos de ouro. Agora surge, no terreno das Bellas Artes, o nome de uma belorizontina: Zina Aita, que se aperfeiçoou no estrangeiro e vai realizar aqui, na sua terra natal, uma exposição de pintura [...] (MATTOS, 1920). 
A exposição de Zina tornava-se, pois, na abertura dos anos 1920, o acontecimento moderno que faltava à cultura do cotidiano de uma Belo Horizonte recém-construída. Sua pintura causa, de forma inédita na cidade, significativa polêmica, abrindo perspectivas para os debates em torno do antigo e do novo, entre a tradição e modernidade. Sua técnica, marcada por uma cor muito viva e pela recusa do cromatismo tradicional, é responsável por estabelecer um verdadeiro confronto entre a arte e o espectador.

Anibal Matos, no papel de curador da mostra e de crítico de arte, comenta sobre a exposição, na Folha de Minas, em 28 de janeiro de 1920, usando o pseudônimo Fly: "Para muita gente, é de esperar, a pintura impressionista e bizarra da senhorita Zina Aita será uma aberração, mas somente para os olhos que não sabem distinguir Belas artes das artes menores [...]" ((MATOS, 1920, p. 26). Mattos, no esforço de explicar o caráter de diferenciação estética do trabalho de Aita, acaba por utilizar categorias que a arte moderna tentava destituir como o conceito de Belas Artes e a distinção entre as artes, qualificando-as entre arte maior e menor.

Há quem identifique semelhança entre a obra de Aita e a de Matisse (VIEIRA, 1997, p. 147) que evidencia, em seus quadros, uma multiplicidade de planos, por meio da cor. As pinceladas largas, justapostas, na superfície da tela, estão presentes na tela Retrato (Imagem 2), exposta por Aita em Belo Horizonte e, mais tarde, apresentada na Semana de Arte Moderna: 


\section{Imagem 2 - Retrato, de Zina Aita}

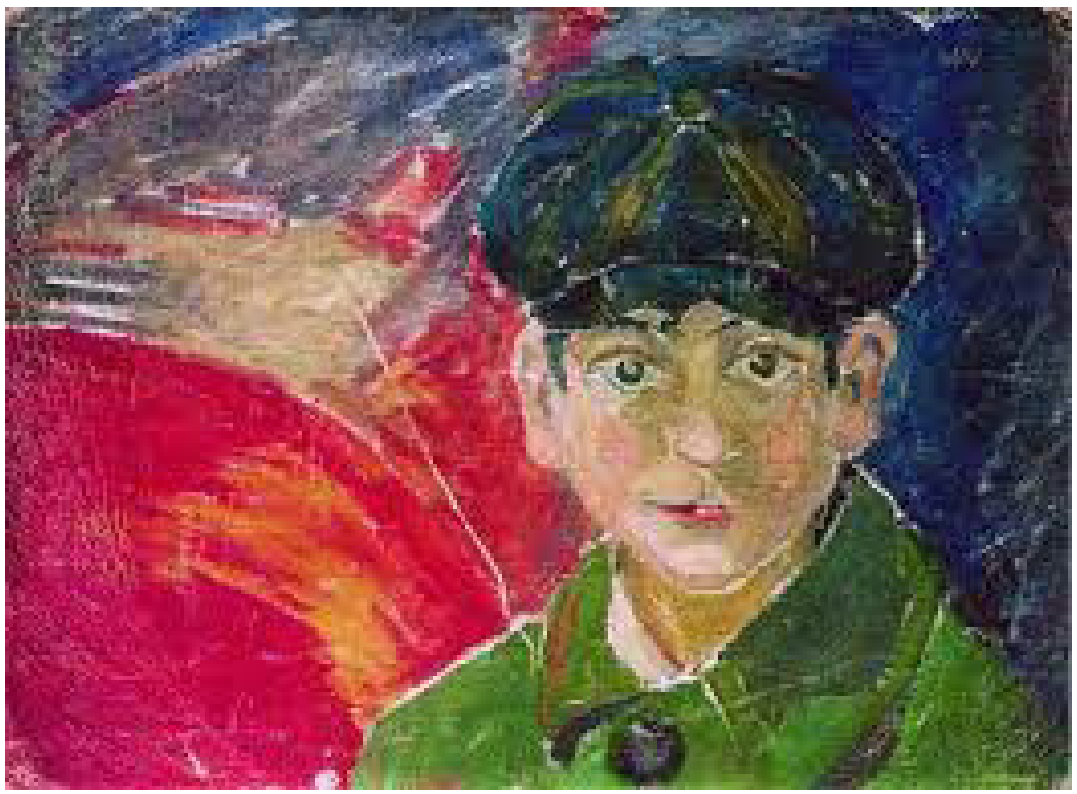

Fonte: Coleção Particular (1920. Óleo sobre tela. 50 x 61 cm).

As manchas coloridas da superfície evidenciam, em pinceladas vibrantes, movimento e sensualidade. A predileção pelos tons de vermelho e de tons puros, primitivos, sugerem uma aproximação com Ataíde, pintor mineiro do século XVIII. Essas cores, provavelmente influências de uma infância e adolescência em terras mineiras, impressionariam vivamente o espírito de Tarsila Amaral, quando veio, em companhia dos Andrade (Mário e Oswald), para uma visita de "reconhecimento" às terras mineiras. ${ }^{7}$

Como o itinerário do grupo se iniciou numa semana santa na vetusta São João Del Rey, o espetáculo de tons quentes, vermelhos, dourados e barrocos exerceram sobre a pintora influência inegável:

$\overline{7}$ Tratava-se da chamada Caravana paulista, de 1924. 
Encontrei em Minas as cores que adorava em criança. Ensinaram-me depois que eram feias e caipiras. Segui o ramerrão do gosto apurado... Mas depois vinguei-me da opressão, passando-as para as minhas telas: azul puríssimo, rosa violáceo, amarelo vivo, verde cantante, tudo em gradações mais ou menos fortes, conforme a mistura de branco. Pintura limpa, sobretudo, sem medo de cânones convencionais. Liberdade e sinceridade, uma certa estilização que adaptava à época moderna. Contornos nítidos, dando a impressão perfeita da distância que separa um objeto de outro. Daí o êxito que obteve na Galeria Percier, rua La Boetie, em Paris, quando fiz, em 1926, a minha primeira exposição (AMARAL, 2010).

Recusando harmonias cromáticas tradicionais, a jovem artista mineira inovou, ressalta a pesquisadora e doutora em artes plásticas, Ivone Luzia Vieira. Sua obra revela a insatisfação com o academicismo, apresentando um contraponto entre o eterno e o fugaz. Os pressupostos que iriam motivar os rapazes revolucionários de 1922, em São Paulo, encontravam acento na pintura cheia de intensidade da mineira Zina Aita - a liberdade de pensamento e expressão.

Aracy Amaral (1972), em O Modernismo brasileiro e o contexto cultural dos anos $20,{ }^{8}$ declara que Anita Malfatti e Yan de Almeida Prado tiveram opiniões coincidentes sobre a obra de Aita. Para Malfatti, as obras da pintora mineira "foram bem modernas"; para Almeida Prado, seus quadros representavam "o melhor da mostra de pinturas". Mário de Andrade, em comentário posterior à Semana de 22, declara que:

[...] em primeiro lugar, e de muito superior às outras, vejo a senhorinha Anita Malfatti - o mais curioso, o mais enérgico e vibrante temperamento feminino que possuímos. Temos ainda as admiráveis coloristas Zina

$8 \quad$ Disponível em: https://www.revistas.usp.br/revusp/article/viewFile/45021/48633. Acesso em 09/02/2018. 
Aita, de primeira ordem nos trabalhos decorativos, e a Sra. Tarsila do Amaral, cuja evolução nesses últimos tempos é surpreendente (ANDRADE, apud BATISTA, 1972).

O pioneirismo de Aita é registrado pela pesquisadora Ivone Luzia Vieira: “[...] sua arte revela a insatisfação com o academicismo, o desejo de inovar por meio do processo dialético entre o eterno e o fugaz [...]" (2027, p. 344). ${ }^{9}$ Sua produção, entretanto, permanece pouco conhecida e grande parte de suas obras não é datada. Para alguns estudiosos, a pintura de Zina Aita desse período aproxima-se do movimento art nouveau e do pósimpressionismo. Passada a turbulência inicial da Semana de Arte Moderna, as três pintoras modernistas - Tarsila do Amaral, Anita Malfatti e Zina Aita - sofreram efeitos diferenciados, destacados ora pela veemência da crítica vindas até mesmo de seus pares, divididos em trincheiras diversas, ora pelo apagamento paulatino de sua participação no turbulento evento paulistano, como foi o caso da pintora Zina Aita.

Malfatti, defendida pelo grupo de modernistas após a conhecida exposição de 1917 e o combativo artigo escrito por Monteiro Lobato (1918), ${ }^{10}$ desacatando as novidades pictóricas que ela trazia da Europa, sofreu, alguns anos depois, uma crítica arrependida de Mário de Andrade. Ele, que comprara a tela $\mathbf{O}$ homem amarelo, declararia, depois, que Anita perdera a mão, em decorrência dos ferozes ataques feitos pelo autor de Urupês e por parcela da imprensa que, em meio à efervescência da Belle Époque tropical, imersa em embates políticos e literários, vivia a confluência e a aclimatação de novas percepções artísticas e um inevitável apego à tradição.

9 Publicado nos anais do XXVI Colóquio CBHA-

10 A exposição de Anita Malfatti, Jornal do Comércio, São Paulo, 11 de janeiro, de 1918. 
Na reflexão de Aracy Amaral (1972), "realmente, pouco se faria de 'moderno' em São Paulo, em 1922, em relação aos movimentos da vanguarda internacional [...]". Em 30 de setembro de 1922, Drummond escreve resenha do romance Os condenados, no Diário de Minas, declarando que era de "São Paulo, terra admirável, onde há café e grandes indústrias, que nos vem o grito do futurismo nacional [...]" (apud CURY, 1998, p. 121), deixando implícito o eclético acordo entre a oligarquia cafeeira, os novos industriais e o grupo de intelectuais que liderava os anseios de revolução artística no país. Nesse pouco de moderno, conforme declaração de Amaral, o grupo de mulheres pintoras - compreensivelmente interligada às escolas e às influências europeias - destaca-se como voz afirmativa de uma nova pintura, questionadora.

Da exposição de Anita Malfatti, em 1917, considerada o acontecimento propulsor para a realização da Semana de 22, à fragmentação e diluição das propostas do "grupo paulista" no aprofundamento de uma tendência nas artes sob uma perspectiva de vanguarda, muito se discutiu e se estuda, mas se nota um desbotado registro acerca da participação feminina, artistas e promotoras, na conhecida Semana de Arte Moderna.

Depois do arrefecimento de Malfatti, devido aos violentos ataques sofridos na imprensa, as cores de Tarsila do Amaral vêm dar seu testemunho artístico internacional e acentuar, no grupo de jovens que se reuniam, entusiasmados, ante uma proposta de nova arte, seu contato com o grande mundo artístico. De seu estúdio, em Paris, ecoavam vozes diferentes da vanguarda europeia, como Picasso, Blaise Cendrars, Cocteau, Brancusi, Léger. Sobre a jovem Aita, pouco ou quase nada se soube, talvez porque ela tenha voltado definitivamente para a Europa, em 1924, onde continuou a trabalhar como pintora e ceramista. 
Passados quase cem anos da Semana de Arte Moderna, muitas indagações persistem. Agenor Barbosa, um dos participantes e idealizadores do famoso festival, foi, pouco a pouco, sendo esquecido da cena artística e intelectual. Na fortuna crítica recolhida sobre o evento, percebe-se que as citações sobre ele vão desaparecendo a partir da década de 1950. Nas teses sobre o Modernismo brasileiro, ele é referenciado como "obscuro", desconhecido", "poeta paulistano", "poeta carioca" ou "poeta da província". Encontramos registros de que ele fez palestras na Vila Kyrial, ao lado de Mário de Andrade, e de que publica na imprensa paulista artigos que propagam a "arte nova", em 1921. Uma das maiores dificuldades em relação ao estudo de sua participação encontra-se no fato de que Barbosa, embora tenha publicado com frequência no Correio Paulistano, nas revistas A Cigarra (1914-1975), Fon-Fon (1907-1945), Panóplia (1917- 1919) e na Revista Brasileira (1855- atualmente Revista da Academia Brasileira de Letras), não deixou livro publicado. Sobre Zina Aita, há estudos de Aracy Amaral e Ivone Luzia Vieira, mas seu nome também foi, aos poucos, esmaecido, chegando mesmo a ser omitido, na cena principal das exposições da Semana de Arte Moderna. Tarsila do Amaral, que não participou presencialmente do festival artístico, ocupa lugar de destaque.

Com o modernismo, definiu-se de modo mais claro uma espécie de colonialismo cultural interno que, partindo de São Paulo e do Rio de Janeiro, alcançou com força Minas Gerais e, de modo atenuado, outros estados brasileiros. A reflexão sobre a participação e o esquecimento dos dois artistas mineiros na Semana de Arte moderna é importante para que possamos entender o modernismo e suas ambiguidades, com seus conflitos internos, erigidos dentro de suas próprias trincheiras. Muitos 
historiadores e críticos fingem não perceber a existência de um vínculo entre o passado e o espírito moderno demolidor que imperou na primeira fase do modernismo nacional. ${ }^{11}$ Por meio dos versos de Barbosa pode-se ler a convivência contraditória entre o passadismo e o espírito moderno, naqueles extremados anos do século XX. ${ }^{12}$ Nas telas de Aita, lemos a influência vanguardista, aliada à contribuição da tradição de Minas Gerais, com suas cores barrocas.

Rubem Borba de Moraes, no ensaio Recordações de um sobrevivente da Semana de Arte Moderna, publicado no Correio Brasiliense, em 21 de fevereiro de 1970, afirma que a teoria modernista não recebeu uma formulação definitiva, apesar de sua tentativa no calor dos fatos. Os jovens integrantes ao núcleo primitivo do movimento não se davam conta da importância e da repercussão que em breve alcançariam: "Nada ficou registrado do resultado das acaloradas discussões, das impressões de leitura que tanto nos influenciaram, das críticas veementes que fazíamos dos autores contemporâneos, das piadas reveladoras de nosso estado de espírito, dos princípios que aceitávamos e das atitudes que tomávamos [...]" (MORAES, 1970, p. 15). Para Moraes, a ausência de fontes primárias sobre o planejamento da Semana fez com que os historiadores se pautassem em material secundário sobre o movimento, como os artigos de Menotti Del Picchia, Mário de Andrade, Agenor Barbosa e Oswald de Andrade, publicados em jornais no ano de 1921. Oswald, para Moraes, não passava de um "vendedor habilíssimo dos novos produtos das artes e da literatura moderna [...]" (MORAES, 1970 , p. 15), que não soube interpretar corretamente a ideologia do grupo modernista.

\footnotetext{
11 A busca de raízes primitivas que trouxessem à tona o Brasil independente e original teve sua inspiração no Romantismo, por exemplo.

12 Mário de Andrade, com sua invulgar sensibilidade, já visitara Minas Gerais, em 1919, para conhecer o simbolista mineiro Alphonsus de Guimaraens.
} 
Os jornais da época estampavam textos doutrinários ao estilo dos manifestos de Marinetti comprados na Livraria Italiana do Tisi, no Largo São Bento. A turma de intelectuais jovens se autodenominava de "futuristas de São Paulo". Menotti Del Picchia, um dos maiores entusiastas do novo credo artístico, segundo Borba de Moraes, tomou Agenor Barbosa como pupilo, sobre quem declararia em publicação presente no Correio Paulistano em 30 de abril de 1921: "Seus poemas são naturalistas integralistas de acordo com as novas correntes estéticas, fixando, assim, numa compreensão integral da função poética de agora, os aspectos da vida violenta e citadina [...]" (MORAES, 2011).

O texto de Moraes, constituído como testemunho importante de quem esteve no protagonismo das preparações do recital de 1922, também revela certo ressentimento de quem não foi suficientemente lembrado. Insinua superficialidade intelectual em Oswald de Andrade, censura o excesso entusiasta de Menotti Del Picchia e, sobre Agenor Barbosa, declara que seus versos eram lidos às gargalhadas, por parte do grupo vanguardista.

No grupo modernista havia subdivisões, contradições, dissensões e atitudes preconceituosas, associadas às vaidades de cada artista. Barbosa, apontado como caipira pelo grupo paulista a que pertencia Moraes, não era um poeta alinhado às requisições de rebeldia que o grupo apregoava, embora tenha sido o único a apresentar, no Theatro Municipal, um poema de dicção nitidamente futurista, como se lê nos versos de Os pássaros de aço.

Em artigo publicado na revista Remate dos Males, em 2013, intitulado A Semana de 22 e a Poesia: Contradições e Desdobramentos, Leandro Pasini menciona o fato de que Menotti Del Picchia abre a conferência do segundo dia da 
Semana de Arte Moderna com trechos de poema de Agenor Barbosa: "Pela estrada de rodagem da via láctea, os automóveis dos planetas correm vertiginosamente [...]", (REBELLO e PAULA, 2020, p. 173). do poema "Canto real da estrada de rodagem", que constaria do livro Poemas da vida e das cidades, como anunciado por Picchia. Pasini ainda se refere ao fato de que Oswald de Andrade, na crônica Literatura Contemporânea, publicada em 12 de junho de 1921, no Jornal do Commercio, reproduz o poema "Os pássaros de aço", de Barbosa, recitado na noite literária do Theatro Municipal. Para Pasini, os poemas mencionados por Menotti no artigo do Correio Paulistano, constituem tentativas canhestras de adaptação ao gosto futurista. No entanto, o estudioso não menciona as crônicas de Sérgio Buarque de Holanda, Oswald de Andrade e Sérgio Milliet, que consideram Agenor Barbosa um dos expoentes da poesia moderna que se escrevia no Brasil nos dois primeiros decênios do século XX.

Em uma de suas crônicas publicadas no Correio Paulistano, em 1922, Agenor Babosa explicaria que não era futurista, mas gostaria de sê-lo, pois considerava o futurismo plenamente de acordo com o mundo moderno. No mesmo artigo, adverte a respeito de sua formação simbolista. Embora não se possa comprovar tal hipótese, o artigo de Barbosa soa quase como uma resposta do poeta às críticas feitas por parte do grupo de intelectuais a sua obra.

As pesquisas sobre a Semana de Arte Moderna, na segunda metade do século XX, contribuem para a exaltação de alguns nomes - Mário de Andrade, Oswald de Andrade e Tarsila do Amaral, principalmente -, em detrimento de outros que foram paulatinamente saindo de cena, ou tendo sua participação 
bastante atenuada, como parece ser o caso do escritor Graça Aranha, sobre quem muitos declararam ter sido o mentor da Semana de 22, pois teria partido dele a ideia da realização do evento.

Este artigo foi pautado prioritariamente em recuperar a presença mineira na Semana de Arte Moderna. O desaparecimento dos dois participantes mineiros não constitui um caso isolado, entre tantos que se envolveram nos preparativos e na realização do evento, que foi gradualmente tomando uma conformação paulistana. Escritores, músicos, pintores, vários participantes da aguerrida Semana saíram de cena, por razões variadas. Uns, conforme se sabe, sucumbiram aos ataques frontais da crítica tradicional, como parece ter sido o caso da pintora Anita Malfatti. Outros, empreenderam novos rumos profissionais, como ocorreu com o mineiro Agenor Barbosa, que encetou bem-sucedida carreira jurídica. Também há que se considerar que, do tumulto de vozes que animaram a defender a "arte nova", poucas foram efetivamente as que inscreveram um talento legítimo nos acontecimentos de 22. A imaturidade dos jovens escritores, a compulsão em abater as influências e o espírito demolidor que desconsiderou escritores legítimos apenas pelo fato de serem tidos como passadistas foram traços reconhecidos por vários participantes do vernissage, passados os anos.

$\mathrm{O}$ fato de Agenor Barbosa ter sido o único poeta mineiro a participar ativamente da Semana de Arte Moderna é suficiente para que se pesquise mais acerca de seu nome e sua produção. Talvez possamos dizer que, como tantos desses nomes que movimentaram os três dias de recital no Theatro Municipal de São Paulo, Agenor Barbosa foi um poeta menor, no sentido que lhe imprime T. S. Elliot em ensaio pioneiro sobre o tema. Prioritariamente, Eliot 
adverte que não tem intenção de definir o que seja poesia ou poeta menor, sob pena de que tal definição desperte um infrutífero debate acerca do que seja poesia maior ou menor, em que, fatalmente, concorreriam avaliações depreciativas. Uma abordagem direta, possivelmente, seria considerar como poeta menor aquele que, não tendo publicado livro ou obra expressiva, integre antologias ou publique em jornais e revistas. São poetas pouco conhecidos individualmente, ou fora do grupo específico que frequentam, mas que, pelo fato de integrarem um grupo, com princípios comuns, apresentam certa unidade, pois pertencem a uma determinada geração literária.

O tema discutido por Eliot serve ainda a determinados casos da poesia brasileira e poderia ser aplicada ao eclético grupo de jovens poetas que participou da Semana de Arte Moderna. Do grupo, poucos tiveram fôlego para atravessar gerações e, ainda assim, os que o tiveram, não mostraram, inicialmente, todo o vigor, refinamento e equilíbrio estético que desenvolveram em sua carreira literária. As reflexões apresentadas por Eliot são importantes quando lidamos com autores que a maioria da população nunca leu ou de que sequer ouviu falar. São reflexões que contribuem não apenas para ler determinado poeta desconhecido, mas, sobretudo, porque deixam pistas importantes para o início de estudos que se estendem fora do caminho das repetições, estudos cada vez mais necessários sobre o Modernismo e seus artistas esquecidos, como Agenor Barbosa e Zina Aita.

A partir dessas rasuras, esquecimentos e exclusões, onde às vezes se inscrevem os preconceitos e onde se reúnem os grupos de poder, sabemos que o primeiro momento do modernismo brasileiro ocorreu sem um projeto de modernização do país, que enfrentava graves problemas estruturais, que iam desde questões 
sanitárias a uma acentuada discrepância social. Houve, pois, um hiato entre o movimento e a própria sociedade que lhe dava suporte. As manifestações modernistas do grupo de 1930, por exemplo, revelam forte tendência ao descentramento em relação ao eixo Rio-São Paulo, abrindo-se a outras manifestações e culturas, vindas principalmente do Nordeste. Existiu, entre os artistas de vanguarda, uma preocupação mais ou menos consciente com a busca e a expressão de uma identidade nacional, paradoxalmente mediada pela cultura europeia. Essas dialéticas também evidenciam paradoxos mais profundos que subtraem vozes, esquecem-se da pluralidade de culturas, gêneros, etnias e religiosidades que constituem a nossa brasilidade. A ideia de Mário de Andrade sobre a mestiçagem brasileira, aplicada, numa perspectiva abrangente, à ideia de intercomunicação, misturas e interdiscursividades, não vingou durante a realização da Semana - que excluiu nomes de fora dos segmentos do poder - e na sequência de estudos que a celebrizaram, nos quais as fraturas da exclusão ficaram mais evidentes. Retomando Boaventura Sousa Santos, os do "outro lado da linha", depois de quase cem anos da realização do combativo festival de artes, ainda precisam ser ouvidos. 
Referências

AMARAL, Aracy. Artes plásticas na Semana de 22. 5. ed. São Paulo, SP: Editora 34, 1998.

AMARAL, Tarsila. Pintura Pau Brasil e Antropofagia. Revista Anual do Salão de Maio. São Paulo, n 1, 1939.

AMARAL, A. O modernismo brasileiro e o contexto cultural dos anos 20. Revista USP, (94), 9-18, 2012, disponível em: https://doi.org/10.11606/issn.2316-9036.v0i94p9-18. Acesso em 13 nov. 2021.

ANDRADE, Mário de. Folhas mortas. In: BATISTA, Martha Rossetti et al. Brasil: primeiro tempo modernista - 1917/29; documentação. São Paulo: Instituto de Estudos Brasileiros USP/IEB, 1972

ANDRADE, Mário de. "O movimento modernista" In: Aspectos da literatura brasileira. $5^{\text {a }}$ ed. , São Paulo, Matins, 1974, p. 235.

BOAVENTURA, Maria Eugênia (org.). 22 por 22. A Semana de Arte Moderna vista pelos seus contemporâneos. São Paulo: EDUSP, 2000.

BRITo, Mário da Silva. História do modernismo brasileiro: antecedentes da Semana de Arte Moderna. São Paulo: Civilização Brasileira. $4^{\mathrm{a}}$ ed., 1974.

CURY, Maria Zilda Ferreira. Horizontes modernistas: o jovem Drummond e seu grupo em papel jornal. Belo Horizonte: Autêntica, 1998. p. 79.

ELIOT, T.S. O que é poesia menor. Disponível em https:// pt.scribd.com/document/370547174/O-Que-e-Poesia-Menor-TS-Eliot. Acesso em 13 nov. 2021.

GONÇALVES, Marcos Augusto. 1922. A Semana Que Não Terminou. São Paulo: Companhia das Letras, 2012. 
MARQUES, Ivan. Cenas de um Modernismo de Província. Drummond e outros rapazes de Belo Horizonte. São Paulo: USP, Editora 34.

MATOS, Aníbal. Uma artista belo-horizontina. Diário de Minas, Belo Horizonte, 20 jan. 1920.

MILLIET, Sérgio. Uma Semana de Arte Moderna em São Paulo. A jovem literatura brasileira. Revista do Instituto de Estudos Brasileiros, São Paulo, 1992. p. 199-2190.

MORAES, Rubens Borba de. Recordações de um sobrevivente da Semana de Arte Moderna. Correio Braziliense, 21 fev.1970. MOISÉS, Massaud. História da literatura brasileira, v. 3, Modernismo, São Paulo, Cultrix, 2019.

PASINI, Leandro. A Semana de 22 e a poesia. Contradições e desdobramentos. Remate dos Males, Campinas, São Paulo, v. 33, n. 1-2, jan./dez. 2013. p.191-210.

PICCHIA, Menotti del. A segunda batalha. Correio Paulistano. p. 04,15 fez. 1922.

REBELLO, Ivana Ferrante e PAULA, Fabiano Lopes de. Uma tristeza min eira numa capa de garoa. Agenor Barbosa: um poeta mineiro na Semana de Arte Moderna. 1ed. Belo Horizonte, ed. Ramalhete, 2020. p. 171.

SOUZA SANTOS, Boaventura de. Para além do pensamento abissal. Novos estudos CEBRAP, nov. 2007. Disponível em: https://www.scielo.br/j/nec/a/ytPjkXXYbTRxnJ7THFDBrgc/?1 ang=pt. Acesso em: 18 ago. 2021.

THALASSA, Ângela. Correio Paulistano. O primeiro diário de São Paulo e a cobertura da Semana de Arte Moderna. Dissertação (Mestrado em Comunicação e Semiótica) - Pontifícia Universidade Católica de São Paulo, São Paulo, 2007. 
VIEIRA, Ivone Luzia. Vanguarda modernista nas artes plásticas: Zina Aita e Pedro Nava nas Minas Gerais da década de 20. Tese (Doutorado em Artes) - Universidade de São Paulo, São Paulo, 1994.

VIEIRA, Ivone Luzia. Exposições de arte moderna no Brasil do século XX: a dialética dos ciclos. Comitê brasileiro de história da arte, 26., 2007, p. 342-352. 